Recibido: 30/11/2020 --- Aceptado: 24/09/2021 --- Publicado: 10/12/2021

\title{
UN RECORRIDO POR LA HISTORIA Y EL DESARROLLO DE LA PRENSA EN MARRUECOS: DESDE SUS ORÍGENES HASTA LA ACTUALIDAD
}

\section{A JOURNEY THROUGH THE HISTORY AND DEVELOPMENT OF THE PRESS IN MOROCCO: FROM ITS ORIGINS TO THE PRESENT}

Hiri Abdelhak. Instituto Superior Internacional de Turismo de Tánger Cómo citar el artículo:

Abdelhak, H. (2021). Un recorrido por la historia y el desarrollo de la prensa en Marruecos: desde sus orígenes hasta la actualidad. Revista de Comunicación de la SEECI, 54, 1-18. http://doi.org/10.15198/seeci.2021.54.e669

\section{RESUMEN}

El propósito de las páginas que siguen es ofrecer una visión panorámica de las características fundamentales de la evolución de la prensa en Marruecos desde sus orígenes en el siglo XIX hasta la actualidad. Creemos que este trabajo resulta muy significativo porque intenta salvar la carencia y el vacío bibliográfico que encontramos con respecto a la historia de la prensa marroquí. En cuanto al valor teórico de este estudio, el mismo se convertirá en un antecedente para futuros trabajos relacionados con la temática, de igual manera, sentará un precedente en cuanto a investigaciones abordadas en la historia del periodismo marroquí.

PALABRAS -CLAVE: Historia, prensa, Marruecos, opinión pública.

\section{ABSTRACT}

The purpose of the following pages is to provide an overview of the fundamental characteristics of the evolution of the press in Morocco from its origins in the 19th century to the present. We believe that this work is very significant because it tries to bridge the lack and the bibliographical void that we find in the history of the Moroccan press. As for the theoretical value of this study, it will become an 
antecedent for future work related to the subject, as well as setting a precedent for research in the history of Moroccan journalism.

KEYWORDS: History, press, morocco, public opinion.

\section{UMA VIAGEM PELA HISTÓRIA E DESENVOLVIMENTO DA IMPRENSA EM MARROCOS: DAS ORIGENS AO ATUAL}

\section{RESUMO}

O objetivo das páginas que se seguem é oferecer uma visão panorâmica das características fundamentais da evolução da imprensa em Marrocos desde as suas origens no século XIX até aos dias de hoje. Acreditamos que este trabalho é muito significativo porque tenta preencher a carência e o vazio bibliográfico que encontramos em relação à história da imprensa marroquina. No que se refere ao valor teórico deste estudo, ele se tornará um precedente para futuros trabalhos relacionados ao assunto, da mesma forma, ele irá abrir um precedente em termos de investigações abordadas na história do jornalismo marroquino.

PALAVRAS-CHAVE: História, imprensa, Marrocos, opinião pública.

\section{Introducción}

La prensa en Marruecos es inseparable de la historia del país y de su realidad política. Para muchos autores es el espejo de su realidad histórica y sociocultural, asimismo es un instrumento indispensable para crear la opinión pública. En este sentido, cabe citar la opinión de Cándido Monzón, quien establece un tipo de relación causa-efecto entre los medios de comunicación y opinión pública:

La opinión pública ha encontrado siempre en los medios de comunicación su mejor medio de expresión [...] Las opiniones son de los públicos, pero su publicidad está en los medios, de aquí que siga oyéndose en la actualidad que la opinión pública es lo que dicen los medios de comunicación. (Ramírez, 2005. p.177).

Atendiendo a esta precisión, podemos inducir que la opinión pública es el efecto de un proceso de un conjunto de ideas expresadas por los medios de comunicación. Así, la gente se entera de lo que sucede en el mundo a través de dichos medios.

Lo que se presenta a continuación es un breve esbozo del panorama que guardó la prensa en Marruecos desde sus orígenes en el siglo XIX hasta actualidad. El período de estudio se extiende a, prácticamente dos siglos. La razón de la elección de este marco temporal se debe, principalmente, a un principal interés nuestro por estudiar uno de los contextos históricos más complejos de la historia del periodismo en Marruecos. En este periodo aparecieron y desaparecieron gran cantidad de periódicos. Para ello distinguimos entre los siguientes períodos históricos: 


\section{Desde 1820 hasta 1912}

En tiempos anteriores a la aparición de las imprentas, el transcurso informativo en Marruecos se canaliza por cuatro medios: en primer lugar, los llamados Raqqas (peatones) (El kettani, 1962, p.17), que son los carteros que actúan en voz alta a nivel urbano los mensajes oficiales:

C'est qu'un bon courrier, courant en moyenne 20 jours sur 30, gagne 40 francs par mois, et il est assurément dans ce pays-ci peu de familles ouvrières qui jouissent d'une pareille aisance.

Es un buen cartero, trabaja en un promedio de 20 días sobre 30, gana 40 francos al mes, en aquel entonces muy pocas familias obreras gozaban de semejante prestigio. (Boutbouqalt, p.116).

En segundo lugar, los Barrāhs que son los carteros que informan al pueblo por todas las noticias dictadas por el majzén; se trata de un aparato informativo tradicional que se encargaban de advertir a las poblaciones cuando se trataba de novedades. En tercer lugar, las mezquitas fueron otro medio informativo, ya que representaban un punto de encuentro en el que se intercambiaban las noticias de las diferentes partes del país. Por último, los comerciantes ambulantes constituían también una fuente importante de difusión de noticias. Estas formas comunicativas tradicionales constituían una importante red de información oral y un verdadero aparato informativo en Marruecos.

En lo tocante a la historia de la prensa escrita en Marruecos en el siglo XIX, debemos empezar aclarando que, aunque Marruecos disponía de una imprenta desde el año 1756 (El kettani, 1962, p.14), no hubo ningún intento de publicarse una edición periodística. En relación a este punto, el historiador marroquí Ibn Azzuz AlHakim presenta la siguiente afirmación:

Aun cuando la industria editorial de libros árabes sobre todo en Fez ha tenido gran auge e importancia; lo cierto es que ningún editor marroquí pensó en hacer un periódico o algo que se le asemejara, hasta el ejemplo de los europeos, franceses y españoles, residentes en el país sirvió de acicate para imitarles.(Azzuz Al Hakim, p.11)

Con estas palabras, Ibn Azzuz emite un mensaje cargado de culpabilidad a los editores marroquíes, por no pensar en publicar ningún periódico en lengua árabe a lo largo del siglo XIX. Otro autor que confirma esta carencia y este desinterés por editar un periódico fue Tayeb Boutbouqalt quien asegura que:

Il est vrai que le Gouvernement Chérifien n'avait pas prêté grand intérêt à la création d'une presse arabe nationale. (Boutbouqalt, p.47)

Es cierto que el Gobierno Cherifiano no había prestado gran interés en la creación de una prensa árabe nacional.

El resultado de esta situación es el hecho de que la prensa extranjera se aprovechó de esta carencia e implantó sus propios órganos en la escena cultural 
periodística marroquí. En efecto, a partir del siglo XIX, el norte de Marruecos recibe una gran oleada de prensa europea. Desde el punto de vista de Adila Mustapha, el movimiento colonialista de las grandes potencias europeas tuvo un papel muy decisivo para el nacimiento y el posterior desarrollo de la prensa extranjera en Marruecos durante el siglo XIX:

En efecto, el desarrollo de la prensa en Marruecos se da en un contexto político internacional fuertemente marcado por el triunfo de las tesis intervencionistas, con todo lo que ello significa de tensa y compleja discusión de repartos territoriales, influencias políticas e intereses comerciales en el entonces denominado Imperio cherifian. (Adila, 2013, p.109).

Una vez expuestas estas precisiones introductorias, corresponde ahora presentar los periódicos que aparecen en este marco histórico, en función del lugar de su aparición y siguiendo un orden cronológico.

\subsection{Periódicos de Tetuán}

En la historia del periodismo marroquí, Tetuán es considerada por muchos historiadores como la cuna del periodismo marroquí, recibe el primer periódico de expresión española que se publica en la misma ciudad. En efecto, en el año 1860 se publica El Eco de Tetuán, un diario que se extiende en cuatro páginas, que fue dirigido por Pedro Antonio de Alarcón. A este respecto, reproducimos las reflexiones de Ibn Azzuz:

A Tetuán le cabe el singular privilegio de haber visto alborear primeramente que ninguna otra población de Marruecos la gran palanca cultural que supone la prensa. (Azzuz Al Hakim, p.17).

\subsection{Periódicos de Tánger}

La ciudad de Tánger, capital diplomática del antiguo imperio de Marruecos, representaba el eje central de la prensa extranjera en nuestro país. Tal como sugiere José González Hidalgo:

Si a últimas del siglo XIX y principios del XX se asiste a un desborda-miento de la prensa local en todas las ciudades y pueblos importantes, en Tánger sobrepasa al de cualquier ciudad por la convivencia de distintas nacionalidades, culturas, religiones, idiomas, etc. Y se acentuará en su época internacional. (González. Estudios Africanos, 1995, 113-133).

La precisión anterior describía la ciudad de Tánger como un auténtico arco iris periodístico de diferentes expresiones lingüísticas; se calcula que, entre 1870 y 1912, había algo más de diecisiete periódicos en idioma francés (Fannan, 2004, p.4). Este hecho se refuerza tomando en consideración que dicha ciudad representaba un punto geopolítico donde se entrecruzan prácticamente todos los intereses de las grandes potencias europeas. En otros términos, la competencia entre las potencias colonialistas tuvo un impacto directo en el desarrollo de la actividad periodística. 
El primer periódico que se publica en Tánger, recibe el nombre de L'Oeil de Tanger, un diario en idioma francés que aparece en el año en 1834 (Fannan, 2004, p.4). En 1870 aparecen dos periódicos: El Mauritano; La Alianza Israelita. Es de apuntarse que esta última publicación tenía su propia imprenta, se editaba en tres lenguas: árabe, español y francés y, se interesaba particularmente por los acontecimientos internacionales y la actividad marítima internacional. En el año 1883, ve la luz el primer número del periódico Al-Magreb Al-Aksa (Fannan, 2004, p.4), que fue fundado por el gibraltareño de origen judío, Gregorio Trinidad Abrines. Este periódico se consideraba el defensor de los intereses británicos en la zona. En el mismo año, aparece otra publicación, Le Réveil du Maroc (El Kettani, 1960, p.140). En este mismo año aparece el diario Tánger Gazzeti en su versión francesa y española.

En lengua inglesa, en el año 1884 ve la luz un semanario de información comercial, The Times of Morroco (El Kettani, 1962, p.142). En 1886 aparece El ECO Mauritano. Este bisemanario en español, fue creado por Issac Toledano, Issac Laredo y el gibraltareño, Agustín Lugaro, quienes importaron de Inglaterra la segunda imprenta que se estableció en Tánger (Larredo, 1935, p.233). En el año 1889 aparece una publicación periodística en árabe, El Moghreb (Marruecos) (El Kettani 1962, p.140). Este periódico es considerado el primero en árabe a nivel nacional. Un año después, nace una nueva publicación en idioma español, El Porvenir dirigido por Francisco Ruiz López.

A principios del siglo $\mathrm{XX}$, Francia ha pasado a ocupar una postura privilegiada en materia periodística. En efecto, se experimenta un cierto auge en la prensa francesa; en 1903 salen a la luz dos periódicos franceses, Le Journal du Maroc, dirigido por David Saurin y, Le Maroc, dirigido por Augusto Terrier, ambos diarios fueron impresos en París. Además, surge otro periódico editado en árabe Assa' āda ( La felicidad) (El Kettani 1962, p.140). Este diario fue fundado por un argelino llamado Mulay Idriss Ibn Mohamed El Khabzaoui Aljazaeri, y fue editado por la Embajada francesa. Es de apuntarse que esta publicación aprovechaba de unas importantes subvenciones estatales francesas, que hicieron de él el periódico de mayor difusión en Marruecos y permanece un medio siglo de vida (1883-1956). En el año 1904, la Embajada de Francia, edita otro periódico de expresión en francés, La Dépêche Marocaine.

Resulta evidente, a tenor de lo apuntado, que la política colonialista europea y la colonia judía desempeñaron un papel destacado en la aparición y el posterior desarrollo de la prensa extranjera en Tánger.

\subsection{La prensa en Fez}

Para muchos historiadores, Fez es la ciudad marroquí que conoce los primeros intentos de la aparición de la prensa árabe, nacional y autónoma (El Kettani 1962, p.140). En efecto, la élite marroquí toma conciencia del peligro que la prensa extranjera representa y, funda en 1906 el primer periódico nacional $A-T a^{\prime} \bar{u}$ (la peste) (El Kettani 1962, p.140), creado por El cherif Sidi Mohamed Ibn Abd El Kebir El kattani. En el mismo año aparece Al-Mūstabid (El tirano) (El Kettani 1962, p.140), 
cuyo dueño es Mohamed Ibn Yahya Assikili. Un año más tarde, sale a la luz otro periódico, Sinān AtKalām (La esencia del habla) (El Kettani 1962, p.190). En el año 1908 nacen dos publicaciones: Al-Mūfäkaha (La lucha) (El Kettani 1962, p.140) y AlFaŷr (El amanecer). Cabe destacar que estas publicaciones critican la línea editorial del periódico imperialista Assa'āda. Asimismo tuvieron un papel importante en dirigir la conciencia pública por los riesgos en que se encuentra la patria, para la toma de conciencia del peligro que suponía la prensa extranjera para Marruecos.

\subsection{La prensa en Rabat}

A diferencia de otras ciudades marroquíes, Rabat no recibe ninguna publicación periodística antes del año 1912, salvo que mencionamos el Bulletin Officiel de L'Empire Cherifien.

\subsection{La prensa en Casablanca}

En la etapa pre-colonialista, la ciudad de Casablanca recibía importantes periódicos franceses. En efecto, en el año 1882 se establece en dicha ciudad marroquí la primera imprenta francesa, Réunis Nord-Sud (El Kettani 1962, p.140). En el año 1901 aparece el periódico, Bulletin de L'Enseignement Public du Maroc. Pocos años más tarde, aparecen los siguientes periódicos: La Vigie Marocaine en 1908 y Le Petit Marocain en 1912. Estas dos publicaciones fueron destinadas al servicio del colonialismo francés y tuvieron una larga vida. Su desaparición data del año 1971.

De lo anteriormente expuesto, se pueden señalar algunas consideraciones generales: en primer lugar, la prensa marroquí precolonialista representa un espejo del cruce de los intereses colonialistas europeos; los periódicos fueron subvencionados por representaciones diplomáticas extranjeras. En segundo lugar, los dueños y periodistas de estos periódicos fueron extranjeros; españoles, ingleses, belgas, franceses, alemanes, judíos protegidos, árabes (libaneses, egipcios, argelinos...). Por último, una de las características peculiares de aquellos periódicos es la temporalidad de su producción, generalmente tuvieron una corta vida.

\section{La prensa en Marruecos: 1912-1956}

Tras la imposición del régimen de Protectorado franco -español, Marruecos a partir del año 1912 se encuentra bajo el llamado Protectorado franco-español. El país está dividido en tres zonas de dominio: el norte y las zonas del sur del Sáhara bajo dominio español. La ciudad de Tánger bajo control administrativo internacional. El resto del país está bajo el control de los franceses. Esta situación tiene un impacto directo sobre el desarrollo de las libertades en general y el desarrollo de la libertad de expresión en particular.

\subsection{La prensa en el protectorado francés}

En la zona francesa, para hacer frente a la prensa nacionalista marroquí y por temor a la instalación de una prensa extranjera adversa a la acción colonialista francesa, el General Lyautey (1925-1912) ha aprobado un decreto ley, el día 27 de abril de 1914: 
Le Dahir du 27 avril 1914 fut promulgué comme première loi visant la codification de la Presse au Maroc. II sínspirait, en principe, de la loi française du 29 juillet 1881 ; mais, sur des points, la législation marocaine était beaucoup moins libérale :

-Elle imposait la déclaration préalable pour faire paraitre un périodique, alors que cette contrainte avait été abolie en France.

- Elle exigeait le dépôt d'un cautionnement s'élevant aa 6000 francs alors que cette mesurée avait été supprimée en France depuis 1881.

El Dahir (decreto real) 27 de abril de 1914 fue promulgado como primera ley que rige la codificación de la prensa en Marruecos. En principio, se inspiraba de la ley francesa del 29 de julio de 1881; pero, sobre los puntos relativos a la legislación marroquí era mucho menos liberal.

-Se imponía la declaración previa para hacer publicar un periódico, cuando esta limitación fue abolida en Francia.

-Se exigía la presentación de una fianza de un valor de 6000 francos, cuando esta medida había sido suprimida en Francia desde 1881. (Biada, 1996, p.94)

Como se ve, esta ley exige, entre otras cosas, que los directores de publicación sean de nacionalidad francesa. El contenido principal de esta ley se resume en el siguiente punto: que antes de publicar cualquier periódico ha de solicitar una previa autorización del procurador general para las publicaciones en árabe o en hebreo. Este marco jurídico dificulta enormemente el desarrollo de una prensa nacionalista marroquí; supone un control total y férreo sobre la misma. Esta situación obligó a muchos académicos de la Universidad Al-Qarawiyyin a recurrir a la clandestinidad para transmitir sus ideas mediante la redacción de unos manuscritos. Tal es el caso de Said Hajji considerado por muchos historiadores el genio precoz de la prensa nacionalista marroquí, quien confecciona por sus propios medios un periódico arabófono clandestino Al-Widad, editado y redactado por sus propias manos.

A diferencia de las publicaciones periodísticas nacionalistas, la prensa procolonialista recibía mayor apoyo, subvención y acompañamiento. A título de ejemplo, Pierre Mas ha podido crear un imperio mediático que controla prácticamente toda la edición periodística. Es más, ha podido fundar su propia agencia de noticias y ha manipulado todos los ingresos de la publicidad. En esta misma línea ilustramos el ejemplo del periódico Assa'āda (La felicidad), que fue muy afortunado y recibía unas importantes subvenciones estatales francesas para gozar de mayor comodidad editorial.

Cabe destacar que a principios de la Segunda Guerra Mundial, Francia estaba bajo dominio alemán, el campo de las libertades se redujo considerablemente; las normativas jurídicas son muy severas; la prensa es sometida al dictamen militar y muchos periódicos desaparecen y sistemáticamente prohibidos o sometidos a la censura. Así, el día 29 de agosto de 1939, se produce un nuevo decreto muy severo 
para limitar la libertad de expresión, que prohíbe divulgar las noticias militares y se crean nuevas células administrativas para la censura y la prohibición de la prensa.

Sin embargo, después de haber dado por zanjada la Segunda Guerra Mundial, se produce un cambio importante en la prensa marroquí: el cuerpo periodístico se divide en dos bloques contrapuestos: por una parte, una prensa nacional que reivindica los derechos legítimos de la soberanía y la independencia y otra, de tendencia procolonialista que defiende la ocupación francesa del territorio marroquí.

Entre los que representa el primer grupo figura la prensa nacionalista, que instrumentaliza todos los medios posibles para reivindicar la independencia del país. Algunos periodistas nacionalistas recurrieron, a veces, a establecer una alianza con los Barrahs para comercializar sus periódicos. Lo que más identifica a la prensa nacionalista es su carácter sensibilizador; sus plumas estuvieron dirigidas al servicio de la legítima cuestión nacional, que fue la reivindicación de la independencia del país. Es de apuntarse que la prensa nacionalista estuvo representada por tres órganos: partidista, sindical e independiente. Respecto a la prensa partidista, el partido Al-Istiqlal publica su primer periódico en árabe, Al-Alam en el 11 septiembre de 1946 y otro en idioma francés, L'Opinion, en 1947, que fue dirigido por Abderrahim Boubid (El Messari, Al-Alam, 11/09/1996, p.11). Por su parte, el partido comunista publica dos semanarios, uno en francés, Espoir (Baida, p.308), y otro de expresión en árabe, pero lo publica en la clandestinidad, Hayāt Ashabāb (Vida de los jóvenes). En lo tocante a la prensa sindical, citamos, L'Action Sindicaly Al-Istiqlal, en los que Al-Mahjoub Ben Sdiq colobaraba activamente. Finalmente, la prensa independiente estuvo representada por el periódico, L'Hebdomadaire Juene Magrébin (Baida, 1996, 313-315).

En conclusión, en tiempos del protectorado francés podemos distinguir entre dos grupos periodísticos: una prensa que reivindica los derechos legítimos de la soberanía y la independencia y otra, de tendencia procolonialista que defiende la ocupación francesa del territorio marroquí.

\subsection{La prensa en la zona española}

A diferencia de la zona francesa donde sólo se autorizaba al periódico procolonialista, Assa'āda, editado por la Residencia General de Francia en Rabat, la prensa árabe en la zona Norte de Marruecos gozaba de mejores condiciones. A este respecto, reproducimos las reflexiones de Ibn Azzuz:

Cabe destacar el florecimiento de la prensa árabe de la zona Norte de Marruecos, ya que contrastaba con escasez de títulos que se daban en el resto de Marruecos, donde solo un órgano árabe, se publicara, como si el espíritu de libertad de prensa [...] Las autoridades del Protectorado francés han prohibido la publicación y circulación de toda la prensa redactada por los marroquíes o consagrada a defender los intereses de estos (Azzuz Al Hakim, 1967, p.11). 
La precisión anterior deja claro que la prensa en la zona española tuvo días de relativa libertad de acción. Además, hay que decir que la prensa en la zona española cubre muchas ciudades y pueblos. En palabras de Adila Mustapha:

Según nuestro propio cómputo, un total de 157 publicaciones periódicas sobre temática diversa, con una periodicidad variable y una paginación diferente ven la luz del día en diversas ciudades y poblaciones del Norte de Marruecos. (Adila, Magriberia, Núm. 8/9, 2013, 275-289).

De lo anterior se desprende el gran interés que ha tenido la prensa en la zona bajo dominio español. En efecto, la prensa árabe que había en Tetuán contaba con majestuosos y brillantes periodistas marroquíes, entre ellos citamos a Mohamed Daoud, quien fue el primero en publicar un periódico nacionalista árabe, Assalām (La paz) en 1933. Otro de los grandes periodistas nacionalistas, Abdeljalek Torres, quien en 1934, publica el periódico Al-Hayāt (La vida). Por su parte, el 03 de febrero de 1937, el nacionalista Mohamed Al-Makki Annasiri, dio luz a una nueva publicación en árabe y español, Al-Wahda Al-Magribiya (La Unidad Marroquí). Conviene remarcar que la prensa nacionalista en el norte de Marruecos, representaba su afán emancipador del país entero, pero nunca estuvo de tendencia regional, su único objetivo es defender la independencia del país entero. Para muchos historiadores, el desarrollo de la prensa árabe en Tetuán, se debe a la abundancia de las imprentas. A este propósito Fernando Valderrama comenta:

Al volver la presencia de España a Tetuán, se crearon imprentas de nuevo, siendo la primera La Papelera Africana, fundada en 1914, a la que siguió la imprenta Córdoba y Vialá, en 1917. En Larache, se creó la primera, que fue la Ibérica, en 1914. Hoy cuenta Tetuán con 12 imprentas, 5 de ellas con caracteres árabes. (Valderrama, 1956, p.746).

En lo que se refiere al marco jurídico de la prensa en la zona española, hay que decir que era regida por el Reglamento de 22 julio 1927, derogado por Dahir de 11 enero 1936. Entre las publicaciones periodísticas en la zona española, podemos citar el ejemplo del periódico El Español, que aparece en el año 1938. Éste es considerado el primer periódico español de Tánger y el protectorado español en Marruecos. Otro periódico importante de la zona española, es el Diario de África, que nace bajo la dirección de don José Carrasco Téllez el día 15 de noviembre de 1943:

El Diario de África es, en mayor medida y por su vida más detallada que su antecesor Marruecos, el órgano de expresión prácticamente oficial del Protectorado. [...] la mayoría de sus articulistas, el tratamiento de la información que le daban sus redactores, el apoyo sucesivo a la labor de los Altos Comisarios, la manera de hablar sobre el Jalifa [...] fueron los habituales de cualquier diario gubernamental (Gil, 2002, p.72).

Resulta evidente a tenor de lo apuntado que se trata de una publicación periodística que se ajusta a la política del Gobierno español. Una vez que se ha expuesto, a grandes rasgos, el desarrollo de la prensa en tiempos del Protectorado, corresponde ahora indicar la evolución de la prensa en Marruecos en tiempos posteriores a la colonización. 


\section{La prensa desde 1956 hasta la actualidad}

En el presente apartado presentaremos las grandes características que definen el desarrollo de la prensa marroquí postcolonialista. Para ello, distinguimos entre los siguientes marcos históricos:

\subsection{La prensa partidista (1956-1990)}

Después de la independencia de Marruecos, Francia deseaba mantener, a través de la prensa, su influencia y sus intereses económicos. El grupo mediático francés Mas (del nombre de su jefe, Pierre Mas) mantiene una fuerte presencia, especialmente mediante sus cuatro periódicos francófonos que continúan libremente editándose: Le Petit Marocain; L'Echo du Maroc; La Vigie Marocaine y Le Courier du Maroc.

El Marruecos independiente rechaza el partido único e instaura el multipartidismo. Una de las consecuencias naturales de este proceso es la aparición de numerosos órganos de prensa de diferentes sensibilidades políticas. Entre los grandes periódicos, citamos el diario Al-Alam (la bandera), órgano oficial del partido Al-Istiqlal (La Independencia), que posee una amplia experiencia profesional. Fundado en 1946, este diario pasa a representar el portavoz que divulga la ideología de los militantes de dicho partido político.

La prensa marroquí post-colonialista estaba muy ligada a las grandes fuerzas ideológicas de la escena política marroquí. En otros términos, el paisaje mediático estuvo fuertemente dominado por una prensa partidista, que ya no tiene por objetivo la lucha contra la colonización, sino la lucha por el poder entre los dos propios partidos políticos. Esta nueva realidad ha permitido un gran auge de la prensa partidista que reinó sobre el paisaje de la prensa escrita durante décadas. De esta manera, una vez creado un nuevo partido se dota de un órgano periodístico como portavoz y difusor de su ideología y de sus ideas políticas (Al-Istiqlal y la Unión Socialista de las Fuerzas Populares).

El punto de partida de este nuevo escenario periodístico fue en el seno del mismo partido Al-Istiqlal, ya que el más antiguo partido en Marruecos ha sufrido una escisión en 1959. Lo que dio nacimiento a un nuevo partido de tendencia izquierdista, llamado la Unión Nacional de las Fuerzas Populares, que se convertirá en la Unión Socialista de las Fuerzas Populares (USFP) en 1975. La UNFP se dotará de inmediato de su órgano oficial en lengua árabe, $A$-Ttahrir, bajo la dirección de Mohammed Basri, su jefe redactor fue Abderramán Yussufi. Lo que abre una guerra político-mediática con el partido conservador de Al-Istiqlal y su diario Al-Alam. La rivalidad política entre los dos partidos, Al-Istiqlal y El UNFP, se hizo sentir nítidamente en la prensa, Attahrir y Al-Alam libran diariamente una batalla de ideas contrapuestas.

Hay que señalar que, para muchos autores, durante este contexto histórico, la prensa marroquí vivió un tiempo inigualable; gozaba de un mayor margen de libertad de expresión. Los periódicos estaban muy politizados; afines a sus líneas editoriales. En otros términos, la profesión de periodismo en esa época se ha convertido en 
sinónimo de militancia política y la prensa era ante todo un portavoz, antes de ser un soporte informativo. Además, contaba con brillantes y majestuosos periodistasmilitantes, que poseían unas plumas literarias de gran calidad profesional. Entre ellos, citamos a Mehdi Ben Barka, Mohamad Hasan Ouazzani, Allal El Fassi, Abdallah Ibrahim, Abderrahman Bouabid.

Es preciso destacar que a pesar de la larga carrera mediática de la prensa marroquí, de los nombres de los periodistas que han dado origen a su popularidad en el mundo árabe, y de la publicación de decenas de periódicos marroquíes desde los principios del siglo XIX, en Marruecos no existía ninguna institución de formación en periodismo. Habrá que esperar hasta el año 1969 para que surja el primer núcleo de formación periodística dirigido por la Fundación alemana Friedrich Neuman. Dicha formación se perfila en dos etapas: la primera que dura dos años, durante la cual los estudiantes reciben clases teóricas. La segunda etapa que se desarrolla en dos años, los estudiantes completan su formación con aspectos relativos a lo técnico y a las prácticas, además de recibir el título oficial de periodista.

En definitiva, la prensa marroquí después de la independencia tenía un carácter institucionalmente de militancia política, ya sea de derecha, de izquierda o monárquica. La prensa marroquí post-colonialista estaba muy dominada por las grandes fuerzas ideológicas de la escena política marroquí. Cada partido político mantiene sus publicaciones como órganos o portavoces de sus propuestas políticas. Los periódicos más prestigiosos están en manos de formaciones políticas. De esta manera, los periódicos Al-Alam y L'Opinion son considerados la voz periodística del partido Al-Istiqlal. A su vez, los dos rotativos: A/- Ittihad Al- Ichtiraki y Libération, son voces periodísticas del partido USFP. Al-Bayane es el diario del Partido del Progreso y el Socialismo (PPS). Al-Haraka para el Partido Movimiento Popular (MP), etc. Con la creación de nuevos partidos de derecha o centro-derecha como el Congreso Nacional de independientes en 1978, el Partido Nacional Democrático (PND) en 1981 y la Unión Constitucional (UC) en 1983, se dotarán de inmediato de sus órganos periodísticos: Attajammoue Al-Watani; Al-Ittihad Addoustouri, etc.

En el mismo orden de ideas, la Ley de Marroquinización de las empresas extranjeras de 1973, hizo desaparecer a muchos diarios extranjeros. Así, la prensa del grupo MAS cambió de denominación y pasó a estar bajo el dominio del grupo marroquí Maroc Soir. Como resultado de esta nueva situación, el diario francés, $L a$ Vigie, recibirá el nombre de Le Soir, y el periódico Le Petit Marocain, se transforma en Le Matin (más tarde, Le Matin du Sahara). Además, en 1974, la Agencia Magreb Arab Press (MAP) (Al-Ittihad Al-Ichtiraki, 1002/1992, p.4), se pondrá bajo la tutela del Estado. Esta situación permite al régimen marroquí de representar una verdadera competencia a la prensa partidista.

A partir de los últimos años de la década de los ochenta, la prensa partidista ha acabado por debilitarse y pronto ha empezado a perder su influencia y de una buena parte de sus lectores, como resultado de la caída de popularidad de los partidos políticos. Algunos periódicos han desaparecido, mientras que otros han sobrevivido gracias, en gran medida, a las subvenciones del Estado. Esta situación favoreció 
enormemente el desarrollo de un nuevo periodismo en la última década del siglo XX y principios del siglo XXI.

\subsection{0- actualidad}

A partir de mediados de los años noventa, el mapamundi periodístico marroquí vivió un profundo cambio. Varias son las motivaciones que han incidido en esta evolución, entre las cuales podemos mencionar las consideraciones políticas favorables; a finales de los años ochenta y principios de los noventa, asistimos a nuevas medidas políticas en el campo de las libertades: la liberalización de la prensa y de los presos políticos, la nueva Constitución de 1990 y la creación del Consejo Consultativo de Derechos Humanos.

A todos estos condicionantes habría que añadir que a principios de la década de los noventa, las grandes novedades tecnológicas comenzaron a revolucionar las técnicas de impresión; la renovación de sus medios técnicos con la introducción de la informática y el color. A esto hay que sumar la debilidad que ha sufrido la prensa partidista tuvo un eco muy positivo en el campo de la prensa.

Los efectos sumados de estos factores tuvieron un gran impacto en el desarrollo de unas nuevas voces periodísticas. En particular empiezan a dar nacimiento a la prensa partidista. Los primeros periódicos independientes, Maroc Hebdo en 1991, el diario Assahifa en 1997, seguido en 1998 por Al Ahdath Al-Maghribia.

El auge de la prensa liberal se precisa con llegada del rey Mohamed VI en 1999. En efecto, la prensa marroquí va a conocer un cambio radical gracias a la globalización, la facilidad de la circulación de la información, los derechos humanos... varios diarios y semanarios en árabe y francés, llamados independientes y no partidistas van a ser creados. Llegan entonces los títulos, Nichane, Al-Massae, Akhbar Al-yawm, y muchos otros diarios y semanales de lengua árabe o de habla francesa. El número de títulos era en 2006 de 398 diarios, revistas y periódicos. Cabe señalar también la aparición de los periódicos regionales incluso en ciudades pequeñas. La prensa se ha convertido en un oficio de pleno derecho gracias a su funcionamiento dictado por empresas especializadas y profesionales, pero sobre todo gracias a la publicidad que es la codicia de todos los medios de comunicación públicos y privados. Cabe destacar que en el año 2004, se da nacimiento al Organismo de Justificación de la Difusión (OJD) como órgano cuyo objetivo es controlar la tirada y difusión de diarios y revistas impresos, proporcionar estadísticas y la negociación de precios de la publicidad.

En nuestros días, muchos periódicos de los partidos políticos han desaparecido y ya no disponen de órganos periodísticos partidistas. Otros experimentan una caída libre en venta y no sobreviven casi más que gracias a la ayuda del Estado. En la actualidad, numerosas son las dificultades que debilitan un buen desarrollo del ejercicio periodístico en Marruecos. En efecto, una serie de limitaciones de carácter tanto estructurales-profesionales como legislativas limitan la puesta en marcha de un buen funcionamiento de la prensa escrita. Entre los graves problemas que enfrenta la prensa escrita marroquí, podemos destacar el hecho de que el número de 
periódicos leídos por los marroquíes es muy modesto. Según un informe del Ministerio de Comunicación, sólo un 1\% de la población marroquí lee prensa escrita:

Presse écrite : Lectorat: A peine $1 \%$ de la population.

Prensa escrita: los lectores: apenas el $1 \%$ de la población. (M.AZ, L'Économiste, 02/05/201; http://leconomiste.com/article/presse-ecritebrlectorat-peine-1-de-lapopulation. Fecha de consulta: 25/05/2019).

La precisión anterior deja claro que el bajo índice de lectura en Marruecos dificulta enormemente el desarrollo de la empresa comercial periodística. Según los datos facilitados por el OJD, en 2017, el número total de ejemplares vendidos cada día en todo el país es de 189662 (Assemblée Générale de I'OJD Maroc, 07 /10/2017. http://www.ojd.ma/Actualites/Observatoire-2017. Fecha de consulta: 25/09/2019). Esta situación se debe principalmente al alto analfabetismo de la población. Además de la falta de hábitos de lectura de prensa y el bajo poder adquisitivo. Otro elemento muy preocupante para la prensa escrita marroquí es la competencia excesiva de la prensa digital. A esto habría que añadir otro fenómeno que vulnera la prensa escrita de pago es el de los periódicos gratuitos que son ampliamente leídos, como L'Intermédiaire, Au Fait, Logic Hebdo.

En lo tocante a los ingresos de la prensa marroquí, hay que decir que provienen de tres fuentes: las ventas, la publicidad y las subvenciones del Estado. En relación a la publicidad hay que destacar que constituye uno de los principales ingresos de la mayoría de los diarios:

L'aide de l'Etat a la presse est devenu l'une des éléments clés de l'économie de la presse dons la mesure ou elle conditionne la suivre de certaines publications en difficulté qui n'arrivent pas par leurs propres moyens a assurer l'équilibre de gestion.

La ayuda del Estado a la prensa se ha convertido en uno de los elementos claves de la economía de la prensa y constituye una importante fuente de ingresos para algunas publicaciones en crisis que no llegan por sus propios medios para asegurar el equilibrio de gestión. (Association des Economistes Marocains, 1996, p.65)

En lo que a la subvención pública se refiere, conviene distinguir entre tres tipos: subvenciones directas otorgadas por el Palacio Real y otras del Ministerio de la Comunicación. También hay otro tipo de ayudas indirectas, tales como: la suscripción gratuita al servicio de la agencia oficial MAP, la gratuidad del transporte y el alojamiento de los periodistas, etc.

En cuanto al marco jurídico que rige el Estatuto de los periodistas profesionales, hay que decir que de acuerdo al dahir número 1-95-9 del 22 de ramadán 1415 (22 de febrero de 1995), el periodista es aquel que tiene por ocupación principal, regular y remunerada, el ejercicio de su profesión, en una o varias publicaciones, diarios 0 periódicos editados en Marruecos, en una o varias agencias de información o en uno o varios organismos de radiodifusión, cuya sede principal está situada en Marruecos. 
El legislador añadió otra condición para poder gozar de la calidad de periodistas profesionales y con el fin de beneficiarse de las ventajas concedidas a los representantes de la prensa por las autoridades administrativas o por cualquier otra institución pública o privada; se trata de ser titular de una tarjeta profesional otorgada por el Ministerio de Comunicación. La misma ley exige que, en el marco del ejercicio de su profesión, el periodista tiene el derecho a acceder a las fuentes de información, respetando la legislación vigente.

En Marruecos existe una sola institución pública de formación en periodismo, se trata del Instituto Superior de la Información y de la Comunicación (ISIC), con sede en Rabat y bajo la tutela del Ministerio de la Comunicación que, además, tiene una capacidad limitada. No obstante, los estudiantes de este instituto se desvían cada vez más de la prensa escrita, optando por la prensa electrónica.

Además de dicho instituto público, existen algunas escuelas privadas de formación en periodismo, principalmente en Casablanca, donde se concentra la mayor parte de los periódicos. Sin embargo, sus estudiantes no son apreciados por los periódicos, ya que la formación que proporcionan no es satisfactoria, debido a la falta de cuerpos docentes profesionales. Sin embargo, en muchas ocasiones frente a una insuficiencia oferta de formación, las empresas periodísticas recurren con frecuencia a los profesores universitarios en determinadas especialidades, en particular la economía, el derecho o los idiomas. Por su parte el grupo mediático Maroc Soir (que edita los dos periódicos L'Économiste y Assabah), ha creado incluso su propia Escuela de Formación en periodismo.

Los periodistas marroquíes, por la naturaleza de su trabajo, se enfrentan a diferentes riesgos de desinformación, de publicación de informaciones erróneas que puedan atentar contra personas o instituciones y perjudicar sus intereses. Lo que les expone a menudo a acciones judiciales. A este respecto, la profesión periodística está dotada de un Código de la prensa.

La organización actual del sector también se basa en una serie de foros que representan a los profesionales. Se trata de la Federación Marroquí de los Editores de Periódicos (FMEJ), la Federación Marroquí de Medias (FMM); y para los periodistas, el Sindicato Nacional de la Prensa Marroquí (SNPM), el Club de la Prensa, la Asociación Marroquí de la Prensa Deportiva (AMPS) y de la Liga Árabe de Periodistas acreditada en Marruecos.

\section{Conclusiones}

A la luz de estas tendencias generales, podemos sintetizar que la historia del periodismo marroquí es polifacética y rica. De lo expuesto anteriormente sobre la historia de la prensa en Marruecos, podemos extraer las siguientes conclusiones:

En primer lugar, desde sus comienzos, el surgimiento de la prensa escrita en el siglo XIX fue un vehículo para promover la labor colonialista europea en Marruecos. Los periódicos de aquella época defendían los intereses de las grandes potencias 
europeas. La prensa marroquí precolonialista representa un espejo del cruce de los intereses colonialistas europeos; los periódicos fueron subvencionados por representaciones diplomáticas extranjeras. Los dueños y periodistas de estos periódicos fueron extranjeros; españoles, ingleses, belgas, franceses, alemanes, judíos protegidos, árabes (libaneses, egipcios, argelinos...). Una de las características peculiares de aquellos periódicos es la temporalidad de su producción, generalmente tuvieron una corta vida.

En segundo lugar, el desarrollo del mapamundi periodístico marroquí en tiempos del protectorado podemos distinguir entre dos grupos periodísticos: una prensa pro colonialista que se desarrolló con amplitud, pero bajo la sombra del protectorado franco español; de igual forma, su libertad de expresión estuvo constante y estrechamente ceñida a la voluntad de estas fuerzas colonialistas. Otro grupo periodístico estuvo relacionado con el llamamiento a la independencia de Marruecos que se asoló con un gran número de periódicos que reivindican los derechos legítimos de la soberanía y la sensibilización entre los marroquíes para la defensa de una nación amenazada por la colonización francoespañola. Muchos periodistas marroquíes vieron a la prensa como un medio para exigir la independencia de Marruecos.

La prensa marroquí después de la independencia tenía un carácter institucionalmente de militancia política, ya sea de derecha, de izquierda o monárquica. Los periódicos marroquíes en la era post-colonialista estaban muy dominados por las grandes fuerzas ideológicas de la escena política marroquí. Esta etapa marca un desarrollo cualitativo en el periodismo en forma y contenido. Han surgido los nombres de los periodistas que desempeñaron un papel principalmente en la cristalización del pensamiento político, intelectual y social marroquí.

En estas dos últimas décadas se produjo un verdadero cambio del paisaje mediático, Así, se dieron luz a muchas revistas especializadas, y muchos otros diarios y semanales de lengua árabe o de habla francesa. Sin embargo, en estos últimos años numerosas son las dificultades que debilitan un buen desarrollo del ejercicio periodístico en Marruecos. Entre los graves problemas que enfrenta la prensa escrita marroquí, podemos destacar el hecho de que el número de periódicos leídos por los marroquíes es muy modesto. Además de la competencia excesiva de la prensa digital y gratuita.

En definitiva, la historia de la prensa en Marruecos desde sus orígenes en el siglo XIX, y hasta la actualidad fue testigo fiel y un instrumento indispensable para conocer el transcurso de los grandes acontecimientos históricos del Reino.

\section{Bibliografía}

Adila, M. (2013) Periodistas y colaboradores de la prensa española en Marruecos, en Intus-Legere Historia, Vol. 103-120. http://intushistoria.uai.cl/index.php/intushistoria/article/viewFile/167/147 
Sanz-Marcos, P. Brand management y tribu consumidora. Un estudio aplicado a las marcas de surf españolas

Adila, M. (2013), Prensa española en Marruecos: periodistas y colaboradores. Tetuán: Publicaciones de la Asociación Tetuán Asmir.

Assemblée Générale de l'OJD Maroc, $07 \quad$ 102017) http://www.ojd.ma/Actualites/Observatoire-2017

Association des Economistes Marocains. (1996). Economie de /'Information: le secteur de la presse écrite du Maroc. Association des Economistes Marocains. Rabat : Association des Economistes Marocains.

Azzuz Al Hakim, M. (1967). La prensa árabe del norte de Marruecos, Colección Magrib16, Rabat: Edición mecanografiada no publicada.

Biada, J. (1996). La presse marocaine d'expression française des origines à 1956. Rabat : Faculté des Lettres et des Sciences Humaines de Rabat.

Boutbouqalt, T. (1996). La politique d'information du protectorat français au Maroc : 1912-1956. Casablanca : Les Editions Maghrébines, Casablanca.

Gil Grimau, R. (2002). La última frontera de Al-Ándalus: estudios sobre la península ibérica y sus relaciones históricas con Marruecos. Tetuán; Publicaciones de la Asociación Tetuán Asmir.

González Hidalgo, José Luis, La prensa gráfica de Tánger, en Estudios Africanos, núm. 14- 15, Madrid, 1995, 113-133.

La

Constitución

marroquí

2011.

http://www.ism.ma/basic/web/ARABE/Textesdeloiarabe/DocConst.pdf

Laredo, I. (1935). Memorias de un viajero tangerino. Madrid: Bermejo impresor.

Núñez Villaverde, J. (2004). Redes sociales en Marruecos. Barcelona: Icaria.

Ramírez, A. (2005). El texto de opinión de la prensa escrita. Las Palmas de Gran Canarias: Universidad Las Palmas de Gran Canarias.

Valderrama Martínez, F. (1956). Historia de la acción cultural de España en Marruecos. 1912-1956.Tetuán: Editora Marroquí.

Valderrama, F. (1956). Historia de la acción cultural de España en Marruecos. Tetuán: Editora Marroquí. 
Sanz-Marcos, P. Brand management y tribu consumidora. Un estudio aplicado a las marcas de surf españolas

\section{Obras en árabe}

$$
\text { فنان، مصطفى. (2014). الصحافة في العصد الجديد.الرباط :مطبعة النورس. }
$$

Fānān, Mūstafa (2014). āssặafa fi al'ahd al-ŷadid. arribat: matba'at annawras الكتاني، زين العابدين1962، الصحافة المغربية نشأتها وتطورها، المجلد الاول (1820-

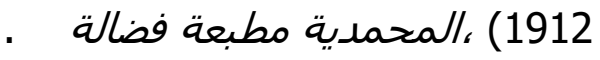

Al-kāatani,zin al-'abidin, āssăḥafa al-magribiyah nash 'atūha wa ta țwūrūha, almūyalad al-'awal (1820-1920), matba'at fadala, al-moḥamadiya, 1962, ș.116.

$$
\text { جمعية عدالة، النديد العزيز( 2008.،الصحافة أمام القضاء: دليل للصحفيين المحامبن، الرباط : }
$$

Anwiḍi, 'abd Al-'aziz, assahāâh amāma al-qađ̣ā'i: dalilun lișșahafiyyina al-muhāmin, ŷam'iyatu 'adālah, arribāt, 2008.

ناجي، جمال الدين2004 ، وسائل الإعلام والصحفيون: موجز آداب المعنة، ، الرباط،: مركز التوثيق والإعلام والتكوين في مجال حقوق الإنسان.

Nāŷi, ŷamāl addin,wasā'il al-i'lām wa-șahafiyūn: mūŷaz ādāb al-mihnah, markaz attawtiq wal-i'lām wa-ttakin fi maŷali ḥuqūqi al-insāni,arribāt,2004.

أصبير،أسماء2009، الصحافة المغربية: بين النص التشريعي وحدود المقدس،، ، دمشق: دار

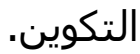

Aṣbir, asmā'2009, aṣahāfah al-magribiyah : bayna annași attašri'liy wa-ḥudūdi almuqaddasi, dārattakwin,dimašq

$$
\text { حسن, كمال ، 》مؤسسو الصحافة الإستقلالية《، العلم، ص.7. ص. }
$$

Ḥassan, kamal, «m ū'assis ū assaḥafa al-istiqlaliya»; A/-'alam, ș.7.

كاني، جاك، 》حول الصحافة العربية بطنجة:لسان طنجة《، ، مجلة دار النيابة ،العدد 1988،18، ص.33.

Kāni, ŷāk, «ḥawla aṣṣaḥāa al-'arabiyah bitanjah :lisān tanjah», maŷalat dār anniyābah,al'adad, 18, 1988, ș..33.

$$
\text { المساري، محمد العربي، لاعلى عتبة الخمسين“، العلم، 19311، 1996/09/11، ص.11. }
$$

Al-mssāri, muḥammad al-'arbi, «'alā 'atabati al-jamsin », Al-'alam,11/09/1996, ș.11. ADILA, Moustapha, «Prensa española del Protectorado: periodistas y colaboradores» en Magriberia, Núm. 8/9, 2013, 275-289.

كمال، حسن، 》الصحافة الوطنية الشمالية من المغرب«، العلم، ص.11.

Kamāl, Ḥasan, « assaḥ̄ăfah ašamāliyah mina al-magrib », Al-'alam, ṣ.11. 
باحدود، محمد، 》الدولة والصحافة بالمغرب《 ، الاتحاد الاشتراكي،1996/02/10، ص4.

Bāḥdūd, Muḥammad,«Addawlah wa -șṣaḥāfah bilmagrib», Al-ittihāà alištirāki,10/02/1996, ș.4.

\section{AUTOR:}

\section{HIRI Abdelhak}

Nació en Tánger (Marruecos). Es doctor en Lengua y Literatura Hispánicas por Universidad Hassan II-Casablanca. Actualmente, es profesor investigador titular en el Instituto Superior Internacional de Turismo de Tánger. Es autor de numerosos artículos publicados en revistas científicas europeas y latinoamericanas, así como es coautor de varios capítulos de libros. Ha ofrecido numerosas conferencias en varias universidades marroquíes, europeas y latinoamericanas. Su área de investigación se centra en el ámbito los medios de comunicación, las relaciones de Marruecos y el mundo ibero e iberoamericano, los modelos de las percepciones recíprocas América Latina-Marruecos cubriendo aspectos tanto de análisis de sus relaciones históricoculturales, como de su tratamiento informativo en el discurso mediático.

ORCID ID: https://orcid.org/0000-0003-1140-85143 